\title{
The End-of-Year Issue
}

When putting together the last issue of the year, one always takes a bit of time to contemplate what has happened over the year, which contents were covered, which conferences visited, which people were interviewed. During this process I uncovered last year's end-of-year issue and found the headline I had chosen for the editorial to be 'Excellent Prospects'. Under current conditions I don't dare to make such a bold prognosis again.

However, I can point in the direction of some topics where, despite of everything, things are moving forward and progress is being made. With Formnext Connect, the digital version of the trade fair for additive manufacturing, right around the corner, it should be mentioned that this industry is proving to be agile and innovative in face of the pandemic. Often referred to as an industrial revolution' by many in this community, things are made possible here that engineers could only dream about a few years ago. It has been and still is exciting to follow this progress.

A somewhat sensitive topic is the dialogue on climate issues. So now seems to be an excellent time to point out: Yes, science is still at work and matters are moving forward. Focusing on the topic of perovskite solar cells here, a story that began with the development of the first cell only in 2009, a new efficiency record has been reported for tandem cells just this year. In our last expert forum in 2020 we will therefore take a closer look at this topic and ask two experts for their scientific opinion. Enjoy reading! 4

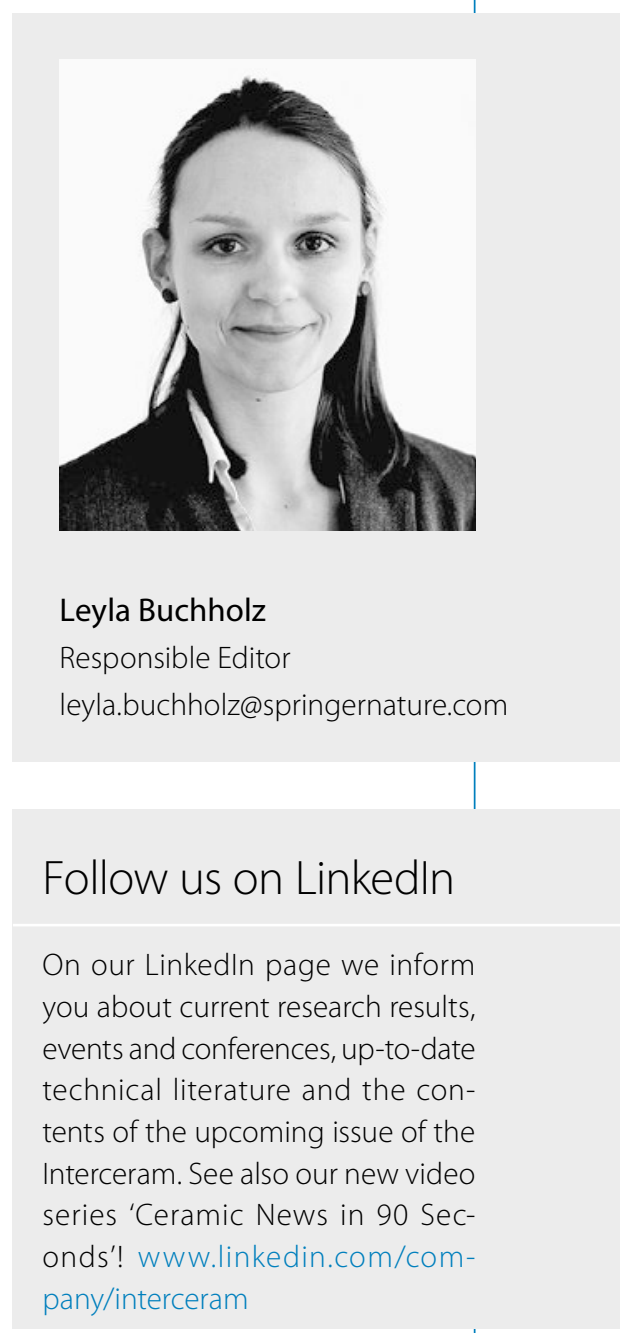

